\title{
Revisiting the Tinto's Theoretical Dropout Model
}

\author{
Maria do Carmo Nicoletti ${ }^{1,2}$ \\ ${ }^{1}$ Centro Universitário Campo Limpo Paulista, C. L. Paulista, SP, Brazil \\ ${ }^{2}$ Computer Science Dept., Universidade Federal de S. Carlos, S. Carlos, SP, Brazil \\ Correspondence: Maria do Carmo Nicoletti, UNIFACCAMP-PMCC, Rua Guatemala, 167, Jardim América, \\ 13231-230 Campo Limpo Paulista, SP, Brazil. Tel: 55-11-4812-9400. E-mail: carmo@cc.faccamp.br
}

Received: May 26, 2019

Accepted: June 14, 2019 Online Published: June 26, 2019

doi:10.5539/hes.v9n3p52

URL: https://doi.org/10.5539/hes.v9n3p52

\begin{abstract}
In the context of university higher education at undergraduate level, the model of student-institution integration, proposed by Tinto \& Cullen and later refined in some of its parts, has often been used to explain the process of dropout/persevere, and even to anticipate such events. This paper approaches the evolution of the Tinto's model since its proposal and reports an analysis of versions of the model found in the literature. The conducted analysis was directed with focus on how to make the model operational, in a way that it could be implemented by universities as an academic computational support system for predicting dropouts. Aiming at its future computational implementation, the analysis approaches the model in relation to its lack of precise definitions of some concepts employed, the loose specification of both, variables and processes involved and questions the extreme importance given to the social integration aspect experienced by students, for explaining dropout.
\end{abstract}

Keywords: higher education, dropout at undergraduate level, models of the dropout problem, Tinto's dropout model.

\section{Introduction}

One of the main problems in higher education nowadays is related to the high dropout rates universities have been experiencing for a few years already, in both types of undergraduate courses: traditional learning as well as e-learning. The seriousness of the dropout problem can be evidenced, also, through the many studies carried out to analyse the problem, to detect the main variables involved, to determine the scope of those variables, to model the dropout process so to organize it into many of its subproblems, to get a better understanding of its dynamic and of the subprocesses it involves, always aiming at a better understanding of the whole problem in an attempt to prevent/minimize it.

The Tinto's model (1973) tries to mirror the iterative process that an undergraduate student experiences, throughout the academic years, pondering about a possible decision between dropout or persevere. Although quite simple, Tinto's model is still largely used by high level educational institutions as a reference model for approaching dropout, providing educational institutions with a way of organizing and directing both, the study and the analysis of the problem, aiming at solving it.

This paper revisits the Tinto's model, since its proposal, by approaching it as the set of the proposed modules, each of them having its own dynamic, regulated by the values of a set of specific variables, most of them related to the student. Modules interact between themselves, providing or receving information and, at the end of the process, the model informs that the student, depending on the values of the variables and the way they have been processed by the different modules, will persevere or will dropout the course. Approached in that way and considering the several similar models discussed in this paper, their corresponding architectures can be translated into the architecture of computational systems that implement an algorithm, based on the values of the involved variables, and where modules can be approached as embedded subsystems. Considering the dropout problem, it is very important to have in mind that the more relevant are the variables that define the modules, and better defined are the processes which deal with those variables, the better will be the outcome of a computational system that implements the simulation of a dropout/persevere process conducted by a student.

The focus of the paper is to emphasize and discuss the importance of variables and modules, particularly those related to the model proposed by Tinto. The outcome of a computational system that implements a dropout/persevere model will be reliable if the system reflects real situations and, also, is based on variables that 
effectively contribute to characterize and predict a situation of dropout, in time to be dealt with before it happens.The paper is organized as follows. Section 2 presents a brief review of three earlier theoretical models on dropout in higher education, which have become the inspirational support for many others that followed. Section 3 presents a panorama of several related research works with focus on university higher education dropout, organized in four groups, depending on their main goal. The Tinto's theoretical model, one of the earlier models mentioned in Section 2 is approached and discussed in details, focusing the original model and its refinement, in Section 4. Section 5 resumes some of the comments and analysis presented throughout the paper and stresses both, the importance of a careful choice of the set of variables that effectivaly support the decision process of dropout or persistence, as well as the importance of having a clear definition and a complete specification of all the involved processes based on the chosen variables.

\section{A Brief Review of Early Theoretically Based Models of the Undergraduate Dropout Process}

Figure 1 is a diagram showing, in chronological order, a group of four early theoretical models for explaining/predicting dropout in high level education institutions. In the figure the models are referred by their names, written above the time line (when names have been assigned to them) and by the associated academic article where they were proposed. Eventual refinements and extensions of models are also included in Figure 1. It can be confirmed in the related literature as well as in the text that follows, that each model has been very relevant on its own as well as very influential for the proposal of other models. The next three subsections present three of them in the chronological order of the year of their proposal. The Tinto's model is discussed in detail in Section 4.

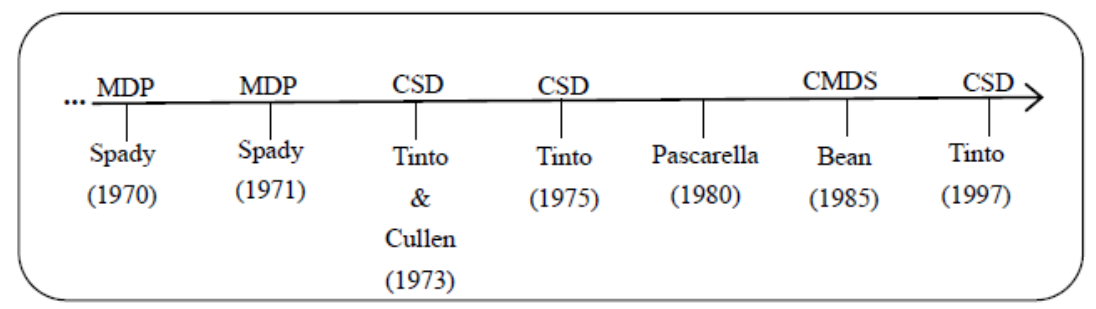

Figure 1. Time line with the earlier influential theoretical models for explaining/predicting dropout

\subsection{The Spady's Model}

The theoretical model for university dropout named Model of the Dropout Process (MDP), proposed and described by Spady $(1970,1971)$, was one of the first models to take into account the sociological aspects embedded in the dropout problem. Spady considered as parts of his model both systems, the academic and the social, that co-exist in an university, since they are integrant parts of the scenario where the process of dropout happens. Spady borrowed from Durkheim's work (1897) the concept of social integration, that plays an important role in his model, as can be seen in Figure 2. Spady (1970, p. 65) was also concerned about the various definitions of the concept of dropout and discusses two operational definitions: (1) "anyone leaving a college at which he is registered" and (2) "those who never received a degree from any college", suggesting that (1) was much easier to handle than (2).

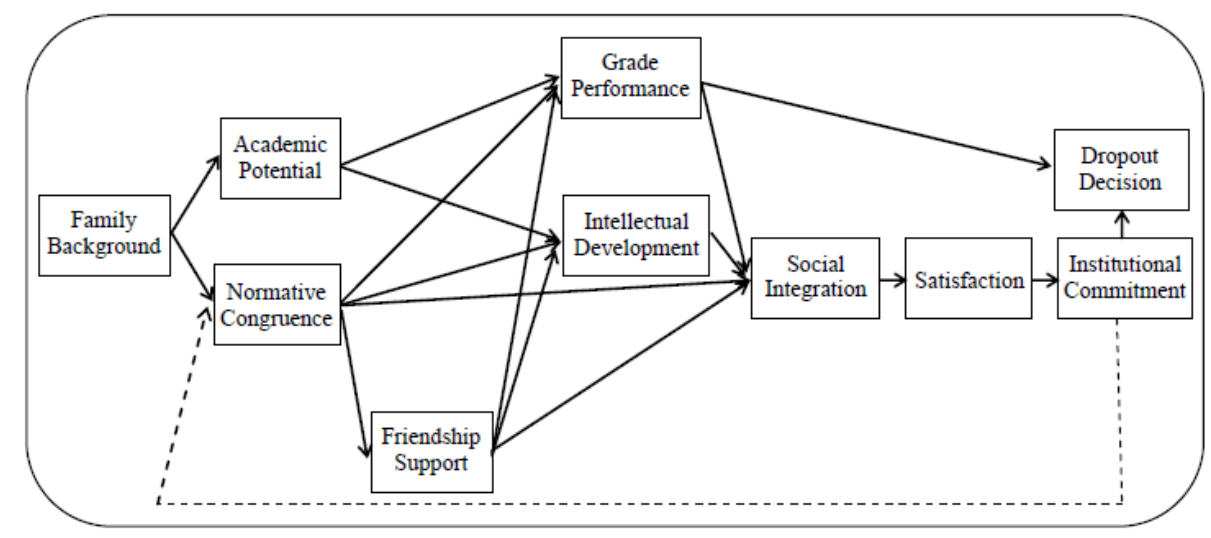

Figure 2. The MDP model of the dropout process (Spady, 1971, 1971) 
In both papers Spady presents a very detailed discussion about the variety of issues and the many variables involved in the dropout problem, and provides, as support for his analysis and comments, results presented by a large number of empirical and theoretical works found in the literature. As pointed out by Aljohani (2016), only after Spady's model was made public that research work, with focus on higher level university dropouts, started to consider the interaction student-institution as one of the issues involved in the problem. It is important to remind though, that the MDP is nearly fifty years old and that in the last fifty years, not only higher educational systems have grown in numbers but also have undergone very substantial changes. Spady (1970) cited 109 research works, distributed by year as: 1 from 1943, 26 from the 50's, 81 from the 60's and 1 from 1970 and Spady (1971) cited 24, distributed by year as: 5 from the 50's, 17 from the 60's and 2 from 1970.

In the discussion of the architecture of the MDP model that follows, the terms variables and components, used by Spady to refer to the ten variables of its model and to the components each variable is associated with, are referred to, in this paper, as modules and variables, respectively. The renaming of both terms aims to ease a future 'translation' of the theoretical model into a computationally implementable system, taking into account that the new names fit better their corresponding computational semantics. So, the terminology used in this paper refers to modules and their associate variables, instead of referring to variables and their associate components. Similar convention is used for the other models that follow. Also, in the context of this article, a variable is approached in a computer programming way i.e., as a string of characters (referred to as variable identifier) associated with a computer storage location that holds values.

As shows Figure 2, the MDP is based on a set of variables grouped in modules, starting with the Family Background module, whose variables influence both, the Academic Potential and the Normative Congruence modules. The concept of Academic Potential can be inferred from its own name with a high degree of certainty. To define some well-known tangible academic variables that reflect this concept is not a hard task. However, the concept of Normative Congruence is specific to the MDP model and involves variables hard to be characterized and, consequently, to be measured. The concept is defined by Spady $(1971$, p. 39) as "... the concept of normative congruence refers to the general degree of compatibility between the dispositions, interests, attitudes, and expectations of the student and the set of behaviors, expectations, and demands to which he may be exposed as the result of interaction with a variety of individuals in the college environment. To the extent that these expectations and influences are highly consistent within a given college context, it is presumed that students whose attributes enable them to accommodate themselves readily to these influences will experience less strain in their general interaction with others, be they fellow students, faculty members or administrators".

A problematic aspect of Spady's model is related to the meaning and operationalization of the Normative Congruence module, considering the critical role it plays in the model; as pointed out by Spady (1970, p. 78) "It represents not only all of the student goals, orientations, interests, and personality dispositions discussed earlier, but the consequences of the interaction between these attributes and various subsystems of the college environment as well".

According to the model, the two previous modules, Academic Potential and Normative Congruence direct and indirectly influence, in a longitudinal approach, all the following modules i.e., Grade Performance, Intellectual Development, Friendship Support, Social Integration, Satisfaction, Institutional Commitment and finally, the Dropout Decision module. Particularly, values of variables in the Institutional Commitment module can influence both modules, the Dropout Decision or then, feedback the Normative Congruence module (represented by the dashed line in Figure 2) and the process iteratively continues from that module on, until hopefully it reaches the Dropout Decision module in one of the iterations.

The Social Integration module stresses the role played by social integration in the MDP model, when combines information from four previous modules i.e., Normative Congruence, Grade Performance, Intellectual Development and Friendship Support, to feed the Satisfaction module. According to the author, Satisfaction could be approached as the outcome of the model or, then, as information to pass on to the Institutional Commitment module, which adds as a variable to the student's decision, his/her commitment to the institution.

\subsection{The Pascarella's Model}

Pascarella (1980) proposes a theoretical longitudinal model with a particular emphasis on the student-faculty informal contact, for representing the dropout/persevere process undergone by higher level education students, as diagrammed in Figure 3 and complemented with the information presented in Table 1. The model is based on five modules namely: Student Background Characteristics, Institutional Factors, Informal Contact with Faculty, Other College Experiences and Educational Outcomes; their interactions, the information they deal with and the processes they implement contribute to support the student's decision of persisting or dropping. 
In spite of the emphasis on the student-faculty informal contact, the model also takes into consideration the vast amount of information that lies underneath the academic life of a student, as some of the previous models do (e.g. Spady's model and Tinto's model). Underneath his proposal is the assumption that informal interactions between students and faculty members would contribute to the student's commitment to the institution as well as improve the social aspect of the student's academic life, which would favor his/her decision of persistence. Pascarella presents a very detailed study of 33 academic works with focus on the impact that student-faculty members interactions can cause on the student's academic life.

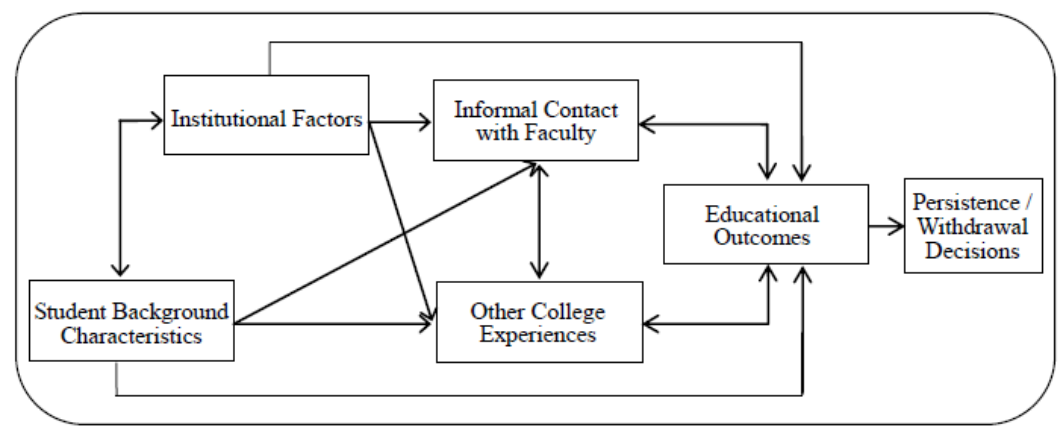

Figure 3. Pascarella's model (1980)

Table 1. Variables involved in the main modules of Pascarella's model.

\begin{tabular}{|c|c|c|c|c|}
\hline $\begin{array}{l}\text { Student Background } \\
\text { Characteristics }\end{array}$ & Institutional Factor & $\begin{array}{l}\text { Informal } \\
\text { Contact with } \\
\text { Faculty }\end{array}$ & $\begin{array}{l}\text { Other College } \\
\text { Experiences }\end{array}$ & $\begin{array}{l}\text { Educational } \\
\text { Outcomes }\end{array}$ \\
\hline $\begin{array}{l}\text { - Family Background } \\
\text { - Aptitudes } \\
\text { - Aspirations } \\
\text { - Personality Orientations, } \\
\text { Goals, Values. Interests } \\
\text { - Secondary School } \\
\text { Achievements \& } \\
\text { Experiences } \\
\text { - Expectations of College } \\
\text { - Openness to Change }\end{array}$ & $\begin{array}{l}\text { - Faculty Culture (e.g. } \\
\text { professional interests, } \\
\text { values, orientations) } \\
\text { - Organizational Structure } \\
\text { - Institutional Image } \\
\text { - Administrative Policies } \\
\text { \& Decisions } \\
\text { - Institutional Size } \\
\text {-Admissions Standards } \\
\text { - Academic Standards }\end{array}$ & $\begin{array}{l}\text { - Context } \\
\text { - Exposure } \\
\text { - Focus } \\
\text { - Impact }\end{array}$ & $\begin{array}{l}\text {-Peer Culture } \\
\text { - Classroom } \\
\text {-Extracurricular } \\
\text {-Leisure } \\
\text { Activities }\end{array}$ & $\begin{array}{l}\text {-Academic Performance } \\
\text {-Intellectual Development } \\
\text {-Personal Development } \\
\text {-Educational / Career } \\
\text { Aspirations } \\
\text {-College Satisfaction } \\
\text {-Institutional } \\
\text { Integration }\end{array}$ \\
\hline
\end{tabular}

The Pascarella's model proposal is interesting because it defines the group of variables associated to each of the five modules of his model, as shown in Table 1. However, many of them are hard to be precisely defined and consequently, to know how to measure them. That is the case, for example, of Openness to Change and Peer Culture. The author used double-arrows between certain modules to imply that the variables that compose the modules may interact, which helps to understand the flow of the information through the whole diagram representing the model. A relevant and difficult aspect to consider in relation to the Pascarella's model (and, in an extent, to the other models) is how to determine at which level the variables in Table 1 contribute to the decision of dropout and, also, how to define them so they can be tangible variables and, still, represent the semantics of their names.

\subsection{The Bean's Model}

It can be found in the literature a few definitions of the concept of dropout having different associated semantics. As commented in Section 2.1, one of the concerns of Spady (1971), when proposing his model, was first to establish the dropout concept the model aimed at. In the study conducted by Bean (1985, p. 36) the same tendency was followed and dropout was defined as: "the failure of a student enrolled at a campus during spring semester to enroll at the same campus during the next fall semester (excluding transfers within the statewide system and students who graduate)".

The title of the work where the Bean's model (1965, p. 36) was published refers to 'dropout syndrome', a term employed with the meaning of "a conscious, openly discussed intention to leave an institution coupled with actual attrition". The Bean's model of dropout syndrome is diagrammed in Figure 4. 


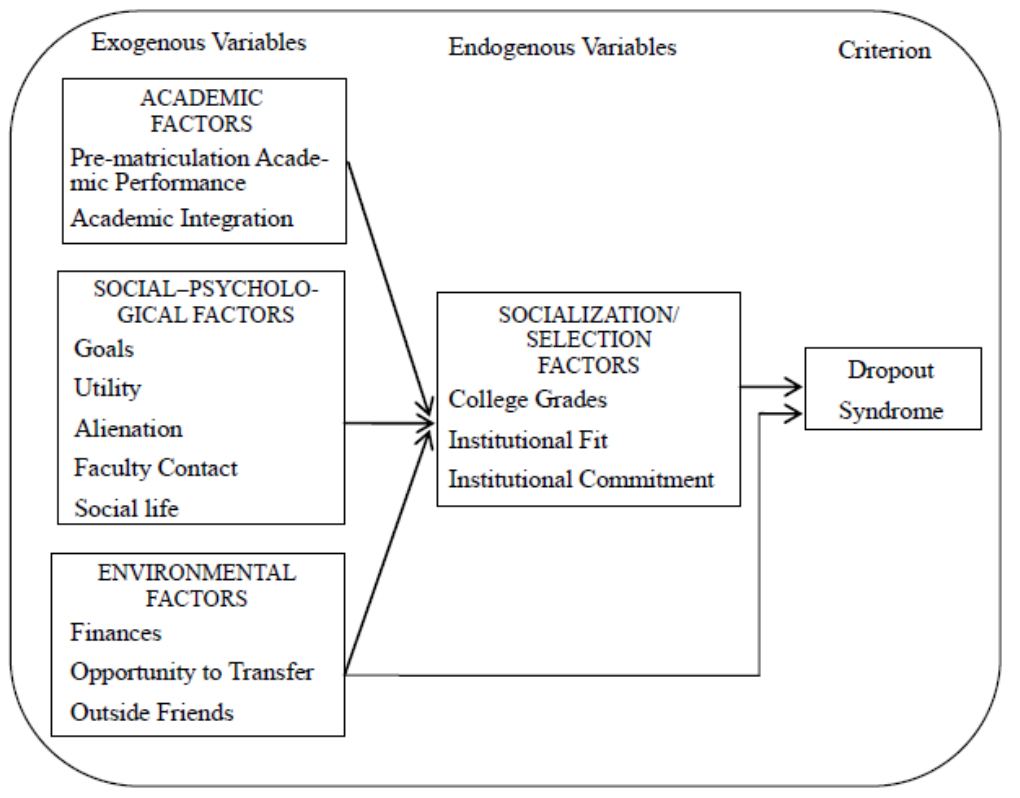

Figure 4. Bean's model of the dropout process characterized as dropout syndrome (1985)

In the Conceptual Model of Dropout Syndrome (CMDS) shown in Figure 4 three modules, each grouping a set of variables identified as exogenous variables, are presented, which are referred to as Academic Factors, Social-Psychological Factors, and Environmental Factors. According with the model, the variables in the three modules influence a fourth module, named Socialization/Selection Factors, that groups three variables, characterized as endogenous variables, named College Grades (of academic nature and consequently, particularly influenced by the variables in the Academic Factors module), Institutional Fit (of social nature) and Institutional Commitment (of personal nature). The Institutional Fit and the Institutional Commitment variables are defined by Bean (1985, p. 37), respectively, as: "a student's subjective impression of the extent to which he or she currently matches the norms and values of his or her peers and mentors" and "institutional commitment indicates the student's personal attachment to the institution extending into the future".

The broad and general definition of both variables suggests that each of them can be approached as a composite variable, that could be represented as a cluster of individual variables. Still, what each individual variable in the cluster would be, and what values it could store, is a decision up to those who use the model for analysing the dropout problem.

Particularly, the variables in the Environmental Factors module may negatively influence the Institutional Fit and Institutional Commitment variables or, then, directly provoke the dropout syndrome, a situation that is represented in Figure 4 by the arrow that connects both modules i.e., the Environmental Factors and the module representing the Dropout Syndrome variable. Although the model has a smaller number of modules when compared with the number of modules in the previous two models, the Bean's model is too general to function as a pragmatic way of analysing dropout.

\section{The Many Different Ways of Approaching the Dropout Problem}

Although the literature in the research area of dropout/persevere in undergraduate courses is broad, most of the research works produced can be related to:

1) empirical validation of early dropout models, such as those described by Stahl and Pavel (1992), by Chrysikos and Ahmed and Ward (2017) and by Durso and Cunha (2018). The study conducted by Stahl and Pavel (1992) initially aimed at investigating the suitability of the Bean and Metzner (1985) model in community college data. When the authors empirically detected that the model was not suitable for the data, they used exploratory factor analysis that induced, as a side effect, the creation of a new model, named by them as Community College Retention Model, that proved to be plausible considering the available college data.

Chrysikos et al. (2017) present an analysis of the use of Tinto's model for identifying the factors influencing the low persistent rates of freshman computer science students, in a higher education institution in the UK. 
The results suggest that the model helped to analyze student retention and the authors only identified two variables that were relevant as far as retention was involved: the initial commitments to both, goals and institution (T1 in Figure 6) and the later commitments to both, goals and institution (T2 in Figure 6).

The main goal of the work by Durso \& Cunha (2018) was to identify variables that could explain the levels of dropout from an accounting course offered by a Brazilian public university. The theoretical guidelines employed by the authors were based on three theoretical models of student's dropout, those proposed by Spady (1970), by Tinto (1975) and by Bean (1980).

In this group of research works it can also be included those characterized as case studies, which not necessarily are based on theoretical models, such as the works by Smith and Naylor (2001), Dekker and Pechenizkiy and Vleeshouwers (2009), by Belloc and Maruotti and Petrella (2010), by Nicoletti et al. (2012) and by Gordon (2016).

2) new proposals of dropout models, which usually are based on combinations of extracts of early well-established models, such as the theoretical model proposed by Kerby (2015) and the theoretical model proposed by Rovai (2003). Kerby considers her model as an expansion of three theoretical models of student's dropout namely, those proposed by Spady, by Tinto and by Bean. The model proposed by Rovai combines the Tinto's model and the model by Bean and Metzner (1985), and takes into account a few other works: those related to online student skills, by Rowntree (1995) and by Cole (2000), the one related to student needs, by Workman and Stenard (1996) as well as the work related to harmonizing the styles of learning and teaching, by Grow (1996), in a new model that aims at explaining persistence in distance education programs.

3) searching for variables/factors that play relevant roles for predicting dropout/persevere, taking into consideration the data available (Giannakos et al., 2017; Murray, 2014; Pidgeon, Rowe, Stapleton, Magyar, \& Lo, 2014; Willging \& Johnson, 2004; Xenos, Pierrakeas, \& Pintelas, 2002).

4) revision works, such that those by Aljohani (2016) and by Demetriou and Schmitz-Seiborski (2011).

\section{The Tinto's Model}

\subsection{The Original Tinto's Model}

The report by Tinto and Cullen (1973) describes the results of a survey commissioned by the U.S. Office of Education, which reviews and presents a theoretical synthesis of research works on dropouts in higher education. The report contains five chapters, each of them briefly described next. In the first chapter various definitions associated with the term dropout are presented and commented. The second chapter reviews data associated with dropout at the undergraduate level, in order to highlight information relevant to the process and, also, to compare rates of dropout in different years. The third chapter deals with the development of a basic theoretical model that seeks to explain evasion as an interactive process that takes place over time, between an individual and a higher education institution he/she belongs to, and the fourth chapter customizes the previously constructed model, to reflect the synthesis of the research works on dropout, discussed in the second chapter. The final chapter, based on the previous two chapters, describes a modified version of the dropout model, identified as Conceptual Schema for Dropout (CSD), that seeks to distinguish between the different types of dropout that, according to the authors, may be (1) voluntary (2) non-voluntary (3) transfer to another institution and (4) permanent.

Since its proposal the theoretical model by Tinto and Cullen (1973), which is referred in this paper as the original Tinto's model, has been the subject of numerous studies and analyses, as well as some extensions and refinements and, also, some criticisms. This article aims to revisit this model of almost fifty years, which has served, in its long history, to support the many attempts made by higher education institutions to inhibit the evasion process in university settings. Figure 5 presents a diagram representing the conceptual schema associated with the dropout process, from university courses, as proposed by Tinto and Cullen (1973).

In a superficial reading of Figure 5, the model initially considers that individuals enter institutions of higher education with an emotional and intellectual baggage that involves their own individual characteristics, a history of their pre-university schooling and their family background. Such baggage has a relevant impact on both, 1) the motivations that push individuals to join an institution of higher education to get a degree, and on 2) the delineation and strengthening of the student's expectations and convictions regarding the completion of the course. The proposed theoretical model refers to this baggage as the individual's commitment to the completion of the course as well as to the educational institution. According to the authors and taking into account the individual's baggage, the factor that most directly impacts his/her permanence in the institution is his/her integration into the university environment. The integration to the academic and social systems of an institution 
takes place under two different types of integration, the normative and the structural. A combination of the initial commitment of an individual and his/her integration into both systems strengthens his/her initial commitment to the completion of the course as well as his/her commitment to the institution. The greater the integration of the individual in both, academic and social spheres, the greater will be his/her commitment to the institution, as well as the greater will be his/her commitment to the goal of persistence and completion of the course.

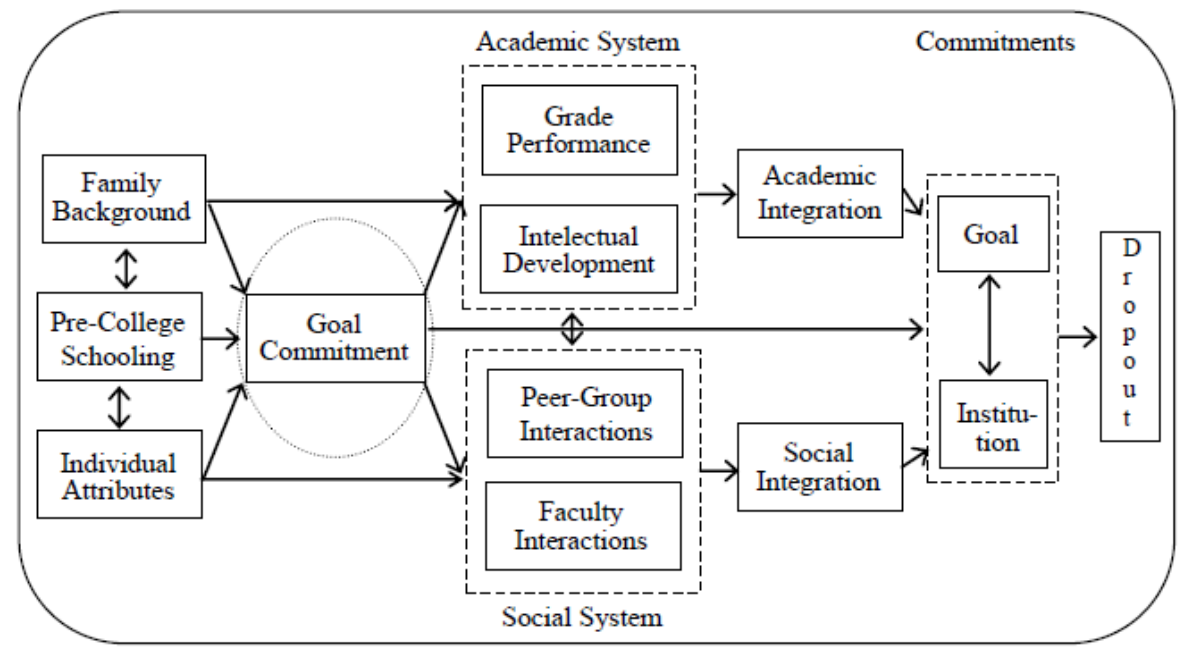

Figure 5. Conceptual schema for dropout (CSD) in college by Tinto and Cullen (1973). The Goal Commitment module has been marked with a dotted oval for future reference and is not part of the original figure

The Tinto and Cullen (1973) original theoretical model can also be approached as a process that starts by receiving, as input data, three sets of variable values, associated with the modules Family Background, Pre-College Schooling and Individual Attributes respectively, and develops based on the results of interactions of an individual i.e., the student, with the institution, where interactions are influenced by the characteristics of both, the individual and the institution. Presumibly the whole process ends when a decision of dropout or persevere is reached at the second time both commitments are evaluated.

\subsection{Some Reflections on the Original Tinto's Model}

As pointed out by the authors, the way the model in Figure 5 was diagrammed, suggests a longitudinal dimension to the dropout process it models, as it could not be any different, considering that dropout is a time-dependent event. Although temporality is implicitly assumed in the model, taking into account the way the diagram has been drawn, temporality itself, as well as it granularity, have not been explicitely contemplated by the model. That makes one wonder about the periodicity of the processes involving reevaluating degrees of commitment to the course as well as to the institution, which are fundamental and critical issues related to the process of dropout, according to the model. Also, the model is not explicit in relation to the time span between the two events of evaluating both commitments of the student, in relation to the completion of the course and in relation to the institution; the description of its proposal does not present a plausible justification for only considering two events of commitment's evaluation.

The original model proposed by Tinto \& Cullen (1973), substantially inspired by the Spady's model, is very general and, considering the way it has been approached and described, it is relatively superficial and difficult to customize with the purpose of modeling a specific real world situation. Also, considering the model proposes to combine data related to:

1) particular characteristics of an individual, his/her pre-university knowledge, his/her family context/background,

2) his/her integration into the academic system and the institution social system which, in a way, reflects and influences his/her commitment to the course and commitment to the institution,

as input for an individual's decision-making regarding his/her persistence or dropout in relation to any institution course, it could hardly be less specific.

The model was proposed without any specific guideline on how to pragmatically approach many of the concepts 
it is based upon. Particularly, the three groups of variables that are input to the model i.e., those that define the modules Family Background, Pre-College Schooling and Individual Attributes, can comprise a relatively large number of variables involved, each of them having a varied degree of influence as far as a) the performance, $b$ ) the commitment to the academic goal and c) the integration into the academic and the social systems of an individual entering the institution are concerned. Given that, many questions can be raised, such as:

1) what type of variables should be considered when describing the Family Background? how tangible can they be? what are the ranges of their values? do some of them have a volatile nature to demand a continuous updating or are they all permanent? Are there uncentainties attached to their values? Could these values come from a source prone to noisy data?

2) the same previous questions apply to variables in the Individual Attributes module.

3) what is the best way to describe the group of variables that defines the Pre-College Schooling module, so to help stressing the purpose of the model?

4) why not take into account the many particularities and peculiarities of the several undergraduate courses offered by universities?

In relation to 4), although many undergraduate courses share a set of characteristics, instantiations of the original Tinto's model that reflect peculiar characteristics of different undergraduate courses, particularly those related to the Academic System module of the model, would tend to be quite different from each other, depending on the specificity of the undergraduate course targeted. For this reason, the model should also take into account, as input, a fourth module, the one that groups the main variables related to the university course targeted by the individual. That would also provide common grounds for comparing model instantiations associated with the same undergraduate course, among different institutions. The model could also be extended by considering the characteristics of the higher education institution as part of a fifth input module. In spite of the fact that many intitutions offer the same course, the way the course is developed by each of them can vary substantially.

In the diagram shown in Figure 5, the great emphasis that the model places on commitments can be inferred by the evaluation of the commitments of an individual to the course, as well to the institution, being considered twice in the diagram: immediately before the start of the course and sometime in future, when the individual has already experienced both i.e., the academic and the social systems of the institution. Since the original model does not consider an associated fixed period of time within which the process of dropout may take place, the model, in this respect, is open to different interpretations to when commitment's evaluation should be carried out throughout the duration of the course.

One could also argue in relation to the emphasis given by the model to college communities (internal as well as external to the institution), as support to the individual's social engagement. Many higher education institutions around the world do not have the culture of college communities playing such an important role on an individual's academic life, to the point of seriously interfering with his/her commitment to getting a degree, as the model stresses. In this way, the premise embedded in the original Tinto's model i.e., that of dropout being a consequence of lack of commitment to the course or to the institution, eventually provoked by the lack of social engagement via college communities, deserves a more in-depth and broad discussion. Two studies related to cultural interrelationships of students' sense of belonging with their institution present interesting results in that respect (Wiseman, Gonzales, \& Salyer, 2004; Hurtado \& Carter, 1997).

It also should be be taken into consideration, when discussing communities and the sense of belonging, that the latest advances of the technology related to information and communicatons, have provoked a deep change in the way people and specially young people, interact, organize as groups, search for information, search for entertainement, socialize and work, among many other activities.

\subsection{Refinements of the Ideas and Concepts Involved in the Original Tinto's Model}

The original Tinto's model (Tinto \& Cullen, 1973), was later published as part of Tinto's academic paper (1975), where some of the theoretical basis of the model were presented in much more detail, such as the Durkheim's theory of suicide (1897) and approached taking into consideration the context of the model.

The paper also presents an in-depth revision of works related to the main aspects of the model, where some of them are discussed in a detailed way, accompanied by a refined textual description and supported by many more explanations in relation to their role in the model, as diagrammed in Figure 5. The two diagrammed models, one by Tinto \& Cullen (1973) (Figure 5) and the other by Tinto (1975), differ only in relation to the initial Goal Commitment module, marked with the dotted oval in Figure 5, which is presented by Tinto (1975) split into Goal Commitment and Institutional Commitment. 
The Goal Commitment module is addressed by Tinto (1975, p. 93) as "an important input variable in the model of dropout because it helps specify the psychological orientations the individual brings with him into the college setting - orientations that are important predictors of the manner in which individuals interact in the college environment". Although emphasized as very important to the model, the Goal Commitment is a very complex issue and, definitely, should be approached as a multidimensional variable, composed by several other variables, each possibly having a multitude of values. There is also the possibility that a few variables that can impact the value to be assigned to Goal Commitment are not known to be relevant to represent the concept. As it can be inferred from the model, independently of the process followed to assign to Goal Commitment a value, the method in charge of determining this value considers only variables related to three modules i.e., the Family Background, Individual Attributes and Pre-College Schooling.

The definition of the process associated with assigning a value to the Goal Commitment itself, can be another demanding and quite hard task to be accomplished, considering the various uncertainties that permeate such task. Although the author gives some examples of influential variables to be considered, how to consider them and how to combine them so to be able to come out with a reliable value, has not been pragmatically addressed. The discussion and considerations given are vague and general to the point of being unfeasible to infer, from them, a possible guideline for identifying and specifying, among other things, several pragmatic issues, such as:

1) how the three modules relate to each other, as the double-headed arrows between them imply;

2) the variables that effectively characterize each of the three modules;

3) the range of values of each one of the variables involved;

4) how to reduce different value ranges related to the same variable, so to provide a common ground for students with very different backgrounds, coming from a very diversified group of pre-college institutions (possibly having different grade scales among themselves, for instance);

5) the relevance of each one of the three modules for determining both degrees of commitment: to the course and to the institution. Are the three modules equally important or should them be weighted by a value representing their importance?

6) how to compose the three sets of variable values, eventually weighted by the weight associated to the module the variable belongs to, to determine values which represent degrees of commitment to the course and to the institution?

In the refinement of the CSD model diagrammed in Figure 6, presented by Tinto (1997), the temporal aspect of the dropout/persevere decision process being developed was made clear by the introduction of a time line at the bottom of the diagram. The author also named each step of the development process, making their corresponding functionalities more explicit. The modules that describe the original CSD continue to be present in the refined CSD version. Next follows a comparison of the structures of both, the original CSD and its refined version.

The three inicial modules of the original CSD i.e., Family Background, Pre-College Schooling and Individual Attributes have been renamed in the refined CSD as Family Background, Prior Schooling and Skills \& Abilities, respectively. Among the three the only module that suffered a slight change was the Individual Attributes, that became the Skills \& Abilities module, in spite of the possible semantics confusion that the change may bring, when identifying the skills and the abilities of an individual. The three modules are identified as Pre-Entry Attributes. The set of variables that define each module, as well as the relevance of each of variable and each module in the dropout/persevere decision process continue to be open to discussion.

The Goal Commitment module in the original CSD suffered a slight change in the refined version, becoming a module with two submodules, one identified as Goal and Institutional Commitment and, the other, as Intentions. A particular change to this module also occurred in relation to the information that is input to it; while in the original version the information come from the three initial modules, in the refined version a fourth source of information was introduced, the one provided by the External Commitments module, not present in the original version. This last change can be considered an strategy for adapting the model to the influences of external communities. 


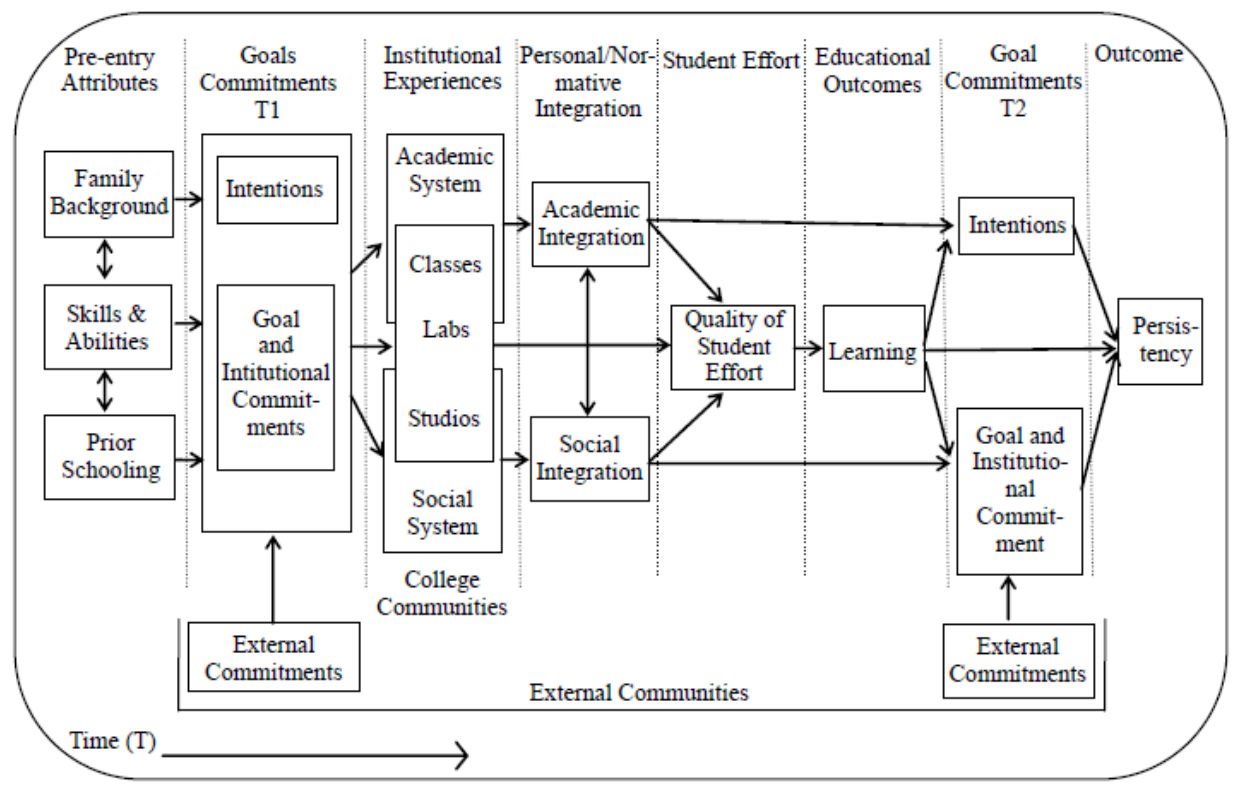

Figure 6. Refinement of the original schema for dropout college proposed by Tinto (1997)

The two evaluation events related to the Goal Commitement module, present in the original CSD, are preserved in its refined version. As can be seen in Figure 6, while the first event, identified by I, and just described, considers one module (having two submodules) passing on information to the Academic System and to the Social System, in the second event, identified by II in Figure 6, each submodule is considered as a module on its own. A possible reason for that, perhaps, is for the model to accomodate the possibility (quite frequent) of, based on the information given by the Academic Integration and the Learning modules, an individual reviews his/her intentions and decides about to persevere or to dropout, without taking into account her/his commitments to the institution or to his/her goal. While in the diagram of the original model there is no connection between the Academic Integration and the Social Integration modules, in its refinment a bidirectional interaction between them has been suggested, by the presence of a double headed arrow between them but how exactly the interaction happens is still an open issue.

In the refinenment two new consecutive logitudinal layers have been introduced. The first, identified by the step named Student Effort, considers the Quality of the Student Effort as a relevant information for representing the dropout/persevere decision process and the second, identified by the step Educational Outcomes, considers the module Learning, for representing the extent of student learning. As commented by Tinto (1997, p. 600) based on a few research works, "... there is a direct relationship between the quality of student effort and the extent of student learning". The second event of evaluating the commitment to both, goal and institution (step named Goal Commitment T2) is the layer immediately before the last layer of the model (step Outcome), as it was originally placed. Both steps of Goal Commitments (the T1 and T2 in Figure 6) take into account information from the module External Commitments, which are linked to the environment outside the Academic and Social systems that represent the institution, named External Communities, representd by the numerous groups of people that interact with college students.

\section{Discussion and Final Remarks}

It was not the intent of the work described in this article to consider a comparison between the few theoretical models of dropout presented. Also it was not the intent of the work to promote a model in detriment of the others. The motivation for presenting a brief description of the early models, in Section 2, was to contextualize the area of research that approches the dropout problem with focus on its modeling, aiming at its better understanding and, consequently, a more directed and refined search aimed at minimizing it.

The choice of the Tinto's model for a more in-depth analysis was motivated by the fact that such model has been cited in a considerable number of research works (Alhojani, 2016), it has been used in many educational scenarios for investigating the dropout problem (Chrysikos et al., 2017) and has contributed to the proposal of hybrid models that share its goal (Kerby, 2015; Rovai, 2003). 
As it can be perceived in this article and in many others that consider various theoretical models for dropout, they all obviously share the same goal i.e., to explain/predict a dropout event, they all have many similar characteristics and they all deal with approximately similar groups of variables. They differ from one another in relation to the emphasis they give to certain aspects of the dropout problem, which contributes to making their diagram-based architectures vary in relation to the number as well as the functionality of their modules. Although the focus of this paper was on the Tinto's model, many of the comments, analysis, questions and considerations presented could be applied to several other models available in the literature.

As briefly mentioned in the Introduction section of this paper, the dropout models reviewed and, particularly, the Tinto's dropout model, can be implemented as computational systems in charge of monitoring students throughout the academic years, aiming at detecting those who can be serious candidates to undergo a dropout process. In a very simplified description such systems simulate the dropout/persevere process experienced by the student by implementing an algorithm which, based on the values of a set of input varibles, calculates the values of the many other variables that define the other modules of the model to, finaly, come to the final decision of dropout or persevere.

As previously reminded, is important to take into account that the variables that define the modules play a critical role as far as the feasibility and the predictability of the intended computational system are concerned. All the variables involved in the system should be carefully chosen and must have an acceptable degree of relevance to the processes that employ them as well to the events of dropout or persevere. The better defined are the processes that deal with these variables, the better will be the outcome of the computational system that implements the simulation of a dropout/persistance process conducted by a student.

The algorithm implemented by a computational system, which is the process that effectively will be in charge so the system can impersonate the student and reach the decision to persevere or to dropout, can be designed using, particularly, two strategies:

1) adopting a conventional way of software system development, implying that a well defined set of decision rules, involving a set of relevant variables, should be specified. The variables involved in the antecedent of the rules should be chosen based on the experience of the faculty members as well as on statistics-based metrics (Tinto, 1997; Chrysikos et al., 2017; Belloc et al., 2010; Paura \& Arhipova, 2014), that help selecting variables statistically relevant for inferring the consequent part of the rule, defined by the decision to persevere or to the decision of dropout. The set of rules should then be codified and embbeded in the system.

2) considering an intelligent subsystem which, based on previous dropout/persevere events, where each event is described by a set of relevant variables, is able to predict if a student, that fits a particular event or a group of similar events, is prone to dropout or not.

Predictive models are strongly dependent on reliable, representative and relevant (to the prediction process) data. As pointed out throughout the text, several dropout models tend to have a loose and general specification of both, the involved variables and the processes that use these variables and that, usually, also determinine the values associated with several of those variables. Taking that into account, models are useful as general guidelines for investigating the dropout/persevere process that happenes in an educational institution but hardly can be effective for supporting the development of computational systems that implement them.

The 'translation' of a model into a predictive computational system can only be accomplished after a careful survey and analysis of the dynamics of the educational institution, followed by the complete identification of all the relevant variables involved, as well as by the specification of processes that deal with (or produce) values for these variables.

It is also mandatory to have all the available information about each relevant variable i.e., how it is used, the nature of its associated value (permanent or transient), its range of values and its degree of relevance related to each process that uses it. It should also be considered that many of the variables involved in the dropout/persevere decision process are very volatile in the sense that their current values may suddenly change as the result of some unpredicted instability and, as consequence, their corresponding degree of relevance in the process may change as well.

The modelling of the dropout problem can be considered an ad hoc process, taking into account that the process itself is highly dependent of several intertwined factors, such as geographic (Murray, 2014), social (Hurtado \& Carter, 1997; Belloc et al., 2010; Paura \& Arhipova, 2014), cultural (Hurtado \& Carter, 1997; Wiseman et al., 2004), temporal and economical (Belloc et al., 2010), among several others, besides those related with the course (Gordon, 2016; Giannakos et al., 2017; Durso \& Cunha, 2018; Xenos et al., 2002) and with the institution; as a 
consequence, it is a process hardly prone to generalization.

\section{Acknowledgments}

The author is grateful to E. T. Pascarella, to CNPq for the research grant PQ 2019 and to UNIFACCAMP, for its support.

\section{References}

Aljohani, O. (2016). A comprehensive review of the major studies and theoretical models of student retention in higher education. Higher Education Studies, 6(2), 18. https://doi.org/10.5539/hes.v6n2p1

Bean, J. P. (1980). Dropout and turnover: The synthesis and test of a causal model of student attrition. Research in Higher Education, 12(2), 155-187. https://doi.org/10.1007/BF00976194

Bean, J. P. (1985). Interaction effects based on class level in an explanatory model of college student dropout syndrome. American Educational Research Journal, 22(1), 35-64. https://doi.org/10.3102/00028312022001035

Bean, J. P., \& Metzner, B. S. (1985). A conceptual model of nontraditional undergraduate student attrition. Review of Educational Research, 55(4), 485-540. https://doi.org/10.3102/00346543055004485

Belloc, F., Maruotti, A., \& Petrella, L. (2010). University drop-out: an Italian experience. High Education, 60(2), 127-138. https://doi.org/10.1007/s10734-009-9290-1

Chrysikos, A., Ahmed, E., \& Ward, R. (2017). Analysis of Tinto's student integration theory in first-year undergraduate computing students of a UK higher education institution. International Journal of Comparative Education and Development, 19(23), 97-121. https://doi.org/10.1108/IJCED-10-2016-0019

Cole, R. A. (Ed.) (2000). Issues in Web-based pedagogy: a critical primer. London: Greenwood Press.

Demetriou, C., \& Schmitz-Seiborski, A. (2009). Integration, motivation, strenghths and optimism: retention theories past, present and future. In: Proc of the 7th National Symposium on Student Retention, 300-312. Retrieved from https://studentsuccess.unc.edu/files/2012/11/Demetriou-and-Schmitz-Sciborski.pdf

Dekker, G. W., Pechenizkiy, M., \& Vleeshouwers, J. M. (2009). Predicting students drop out: a case study. Educational Data Mining, 41-50. Retrieved from

http://www.educationaldatamining.org/EDM2009/uploads/proceedings/dekker.pdf

Durkheim, D. E. (1897). Suicide: a study in sociology. The Free Press, Reissue edition, 2010 (originally published in French).

Durso, S. O., \& Cunha, J. V. (2018). Determinant factors for undergraduate student's dropout in an accounting studies department of a Brazilian public university. Educação em Revista (EDUR), 34, e186332. http://dx.doi.org/10.1590/0102-4698186332

Giannakos, M. N., Aalberg, T., Divitini, M., Jaccheri, L., Mikalef, P., Pappas, I. O., \& Sindre, G. (2017). Identifying dropout factors in information technology education: a case study. In: Proc, of 2017 IEEE Global Engineering Education Conference (EDUCON), 1191-1198.

https://doi.org/10.1109/EDUCON.2017.7942999

Gordon, N. A. (2016). Issues in retention and attainment in Computer Science. Higher Education Academy, University of Hull, 23 pgs. Retrieved from

https://www.heacademy.ac.uk/knowledge-hub/issues-retention-and-attainment-computer-science

Grow, G. O. (1996). Teaching learners to be self-directed. Adult Education Quartely, 41(3), 125-149. https://doi.org/10.1177/0001848191041003001

Hurtado, S., \& Carter, D. F. (1997). Effects of college transition and perceptions of the campus racial climate on latino college students' sense of belonging. Sociology of Education, 70(4), 324-345. https://doi.org/10.2307/2673270

Kerby, M. (2015). Toward a new predictive model of student retention in higher education: an application of classical sociological theory. J. College Student Retention: Research, Theory and Practice, 17(1), https://doi.org/10.1177/1521025115578229

Murray, M. (2014). Factors affecting graduation and student dropout rates at the University of KwaZulu-Natal. South African Journal of Science, 11(11/12), 6. http://:dx.doi.org/10.1590/sajs.2014/20140008

Nicoletti, M. C., Reali, A. M. M. R., Dias, T. C. M., \& Abib, S. (2012). Survey, categorization and analysis of the 
main causes for dropout frm the UFSCar-UAB-Pedagogy Course (períod: 2007-2011) (in Portuguese), Proc. of the IX Congresso Brasileiro de Ensino Superior a Distância (ESUD 2012), 1-14.

Pascarella, E. T. (1980). Student-faculty informal contact and college outcomes. Review of Educational Research, 50(4), 545-595. https://doi.org/10.3102/00346543050004545

Paura, L., \& Arhipova, I. (2014). Cause analysis of students' dropout rate in higher education study program. Procedia-Social and Behavioral Sciences, 109, 1282-1286. https://doi.org/10.1016/j.sbspro.2013.12.625

Pidgeon, A. M., Rowe, N. F., Stapleton, P., Magyar, H., \& Lo, B. C. Y. (2014). Examining characteristics of resilience among university students: an international study. Open Journal of Social Sciences, 2, 14-22. https://doi.org/10.4236/jss.2014.211003

Rowntree, D. (1995). Teaching and learning online: A correspondence education for the 21st century? British Journal of Educational Technology, 26(3), 205-215. https://doi.org/10.1111/j.1467-8535.1995.tb00342.x

Rovai, A. P. (2003). In search of higher persistence rates in distance education online programs, Internet and Higher Education, 6, 1-16. https://doi.org/10.1016/S1096-7516(02)00158-6

Smith, J. P., \& Naylor, R. A. (2001). Dropping out of university: A statistical analysis of the probability of withdrawal for UK university students. Journal of the Royal Statistical Society-Series A, 164, 389-405. https://doi.org/10.1111/1467-985X.00209

Spady, W. (1970). Dropouts from higher education: an interdisciplinary review and synthesis. Interchange, 1(1), 64-85. https://doi.org/10.1007/BF02214313

Spady, W. (1971). Dropouts from higher education: toward an empirical model. Interchange, 2(3), 38-62. Retrieved from https://link.springer.com/article/10.1007/BF02282469

Stahl, V., \& Pavel, D. M. (1992). Assessing the Bean and Metzner model with community college student data. Annual Meeting of the American Educational Research Association, 49. Retrieved from https://archive.org/details/ERIC_ED344639/page/n1

Terenzini, P. T., \& Pascarella, E. T. (1980). Toward the validation of Tinto's model of college student attrition: A review of recent studies. Research in Higher Education, 12(3), 271-281. https://doi.org/10.1007/BF00976097

Tinto, V., \& Cullen, J. (1973). Dropout in higher education: a review and theoretical synthesis of recent research. Office of Education (DHEW), Contract OEC-0-73-1409, 99. Retrieved from https://files.eric.ed.gov/fulltext/ED078802.pdf

Tinto, V. (1975). Dropout from higher education: a theoretical synthesis of recent research. Review of Educational Research, 45(1), 89-125. https://doi.org/10.3102/00346543045001089

Tinto, V. (1997). Classrooms as communities: exploring the educational character of student persistence. The Journal of Higher Education, 68(6), 599-623. https://doi.org/10.1080/00221546.1997.11779003

Willging, P. A., \& Johnson, S. D. (2004). Factors that influence students' decision to drop out of online courses. Journal of Asynchronous Learning Networks, 13(3), 115-127. https://doi.org/10.24059/olj.v13i3.1659

Wiseman, R. L., Gonzales, S. M., \& Salyer, K. (2004). A cross-cultural analysis of students' sense of community, degree of involvement, and educational benefits. Intercultural Communication Studies, XIII-1, 173-190. Retrieved from https://web.uri.edu/iaics/files/14-Richard-L.-Wiseman-Star-M.-Gonzales-Kimberly-Salyer.pdf

Workman, J. J., \& Stenard, R. A. (1996). Student support services for distance learners. DEOSNEWS, 6(3). Retrieved from https://learningdesign.psu.edu/assets/uploads/deos/deosnews6_3.pdf

Xenos, M., Pierrakeas, C., \& Pintelas, P. (2002). A survey on student dropout rates and dropout causes concerning the students in the course of informatics of the Hellenic Open University. Computers \& Education, 39(4), 361-377. https://doi.org/10.1016/S0360-1315(02)00072-6

\section{Copyrights}

Copyright for this article is retained by the author(s), with first publication rights granted to the journal.

This is an open-access article distributed under the terms and conditions of the Creative Commons Attribution license (http://creativecommons.org/licenses/by/4.0/). 